\title{
Article
}

\section{Intermittent attendance at breast cancer screening}

\author{
Padraic Fleming, ${ }^{1}$ Sinead O'Neill, ${ }^{1}$ Miriam Owens, ${ }^{2}$ Therese Mooney, ${ }^{1}$ Patricia Fitzpatrick, \\ ${ }^{1}$ Programme Evaluation Unit, National Cancer Screening Service, Dublin; ${ }^{2}$ School of Public Health, \\ Physiotherapy and Population Science, University College Dublin, Ireland
}

Significance for public health

All breast cancer screening programmes strive to achieve and maintain a high level of attendance, as this is essential to reduce breast cancer mortality, together with cancer detection. While non-attendance has been widely studied, little is known about intermittent attenders. It is unclear why a woman chooses not to attend her breast screening appointment but then decides to respond positively to screening invitation two or more years later. The literature identifies many reasons why some women choose not to attend; but this study distinguishes those who then change their mind and return to screening. This study explores a sub-set of non-attenders which have, to date, been largely ignored, or grouped with people who never attend. This study will inform those struggling with non-attendance in their population based health programmes and will help to tackle the problem of non-attendance, which has adverse affects both economically and epidemiologically.

\section{Abstract}

Background. To determine why women skip rounds and factors influencing return of previous non attenders (PNAs) to breast screening.

Design and methods. Retrospective, quantitative, structured questionnaire posted to 2500 women. First PNAs did not attend their first screening appointment in 2007/2008 but then attended in 2010; First Controls first attended in 2010 without missed previous appointments. Women who attended screening in 2006 or earlier then skipped a round but returned in 2010 were Subsequent PNAs; Subsequent Controls attended all appointments.

Results. More First Controls than First PNAs had family history of cancer $(72.7 \%$ vs $63.2 \%$; $\mathrm{P}=0.003)$; breast cancer $(31.3 \%$ vs $24.8 \%$; $\mathrm{P}=0.04)$. More PNAs lived rurally; more First PNAs had $3^{\text {rd }}$ level education $(33.2 \%$ vs $23.6 \% ; \mathrm{P}=0.002)$ and fewer had private insurance than First Controls (57.7\% vs $64.8 \%$; $\mathrm{P}=0.04)$. Excellent/good health was reported in First PNAs and First Controls (82.9\% vs 83.2\%), but fewer Subsequent PNAs than Subsequent Controls (72.7\% vs 84.9\%; $\mathrm{P}=0.000$ ). Common considerations at time of missed appointment were had mammogram elsewhere (33\% First PNA) and postponed to next round (16\% First PNA, 18.8\% Subsequent PNA). Considerations when returning to screening were similar for First PNAs and Subsequent PNAs: I am older (35.4\%, 29.6\%), I made sure I remembered $(29 \%, 23.6 \%)$, could reschedule $(17.6 \%, 20.6 \%)$, illness of more concern $(16.5 \%, 19 \%)$. More First PNAs stated my family/friends advised (22.3\% vs $15.2 \%)$ or my GP (12.6\% vs $4.6 \%)$ advised me to attend, heard good things about BreastCheck (28.8\% vs 13.6\%).

Conclusions. Intermittent attenders do not fit socio-demographic patterns of non-attenders; GP recommendation and word of mouth were important in women's return to screening. Fear and anxiety seem to act as a screening facilitator rather than an inhibitor.

\section{Introduction}

Reduction in breast cancer mortality has been widely accredited to organised population based mammographic screening programmes. ${ }^{1-3}$ All breast cancer screening programmes strive to achieve and maintain a high level of attendance, as this, together with cancer detection, is essential to reduce breast cancer mortality. ${ }^{4}$ BreastCheck, the National Breast Screening Programme in the Republic of Ireland was established in 2000. BreastCheck invites women aged 50-64 years to be screened by personal invitation on a two year cycle, with a prearranged appointment date and time. In the first round of screening a woman will receive a reminder letter with a pre-arranged appointment date and time if she does not attend the first appointment. In subsequent rounds, a woman who did not attend in the previous round will receive only one invitation with a prearranged appointment date and time. Mammograms and resultant assessments or treatment following screening are free of charge. Initially screening was confined to women resident in the eastern half of the country, but since 2007 screening is offered to women throughout the country. Prior to the rollout of BreastCheck in a region, asymptomatic women were referred privately for screening mammograms and symptomatic women were referred either to the public symptomatic breast service or to a consultant in the private sector, where they would have had a mammogram.

Screening is carried out at four static units and at a number of associated mobile units. The BreastCheck eligible population uptake rate for screening in 2010 was $74 \%{ }^{5}$ Women in follow up care for breast cancer, women not contactable by the postal services, women who have a physical or mental incapacity which precludes screening and women with terminal illness who have contacted the programme to inform BreastCheck of their prognosis are deemed ineligible to be screened through the national programme. Women may be suspended from BreastCheck if they are on extended vacation or working abroad, have had a mammogram outside the national programme within the previous year or decide to defer an appointment until the next round. All other women in the age range 50-64 are invited for screening.

In addition to those women who fail to attend ever, there is a group of women who skip rounds, either one or several, and then return to a screening programme. For the purpose of this study we define a Previous non attender (PNA) as a woman who has failed to attend in the previous round or multiple previous rounds including the penultimate, but was re-invited in 2010 and attended. While non-attendance has been studied, ${ }^{6-13}$ little is known about intermittent attenders. For first screening PNAs it is unclear why a woman chooses not to attend when first invited but then decides to respond positively two years later. For subsequent screening PNAs these women arise from a minority group, as $88 \%$ of all women screened by BreastCheck returned for subsequent screening in $2010 .^{5}$ The literature identifies many reasons why some women choose not to attend; ${ }^{6}-13$ but what distinguishes those who then change their mind and return to screening is uncertain. Significantly more of those who have attended 
BreastCheck at least once return even after skipping one or more rounds than women who have never attended ( $45.7 \%$ vs $21.2 \%){ }^{14}$

Törnberg et al. examined participation in the Swedish breast screening programme and found a cohort of women they referred to as temporary participants, i.e. women who participated in one to four of the five rounds offered overall (38.5\%); $53 \%$ attended all five rounds, $72 \%$ at least four. ${ }^{6}$ Similar to BreastCheck findings noted above, ${ }^{14}$ for those women who were non-participants at the first round the likelihood of being a permanent non-participant was much greater than in those who had attended screening ever. Attendance at the first screening round appears to be of importance in order to convince women to return at further rounds in the future. ${ }^{6-8}$ The aim of this study was to determine the reasons why women skip rounds and the factors influencing return of PNAs to breast screening.

\section{Design and Methods}

A random sample was ascertained from all women on the BreastCheck database, who fitted the parameters of each of the four sub-groups. All four sub-groups were selected ensuring that the most recent attended appointment was in the same year (2010) in order to allow for other influencing factors such as media coverage and national health promotion campaigns. Women who failed to attend their first national population based BreastCheck appointment for screening in 2007 or 2008 but then attended in 2010 were termed First PNAs. We identified a similar sample of women who were first invited and attended in 2010, having not missed previous appointments, to serve as First Controls.

Women who attended all offered appointments for screening in 2006 or earlier, then failed to attend their subsequent appointment for screening in 2007 or 2008 but returned to screening in 2010, were termed Subsequent PNAs. Controls for this group were women who had attended all appointments for screening, including an appointment in 2010. We confined our sample to those with an outcome of normal mammogram. Women who were recalled for further investigation were excluded.

Recruitment was by letter sent with postal questionnaire. A Freepost envelope was included for return of questionnaire. The questionnaires were anonymous and subjects could not be identified. Consent to participate was implied by the return of completed questionnaire. A reminder with a copy of the questionnaire was sent to all participants to achieve the final response rate. Questionnaires were sent to arrive a minimum of five weeks after the most recently attended appointment, allowing sufficient time for a normal results letter to be received. Reminder letters and questionnaires were sent two weeks after the original batch were sent. The questionnaire was developed upon findings from published studies examining non-attendance at breast screening programmes. ${ }^{15-19}$ A core questionnaire was devised for PNAs, modified slightly to reflect differences between First PNAs and Subsequent PNAs. The questionnaire initially addressed recall of the invitation for screening at most recent (attended) appointment and for previous (non-attended) appointment and level of agreement with a series of statements relating to breast screening. A list of possible considerations at the time of the missed appointment was presented and respondents were asked to tick all that applied. A list of possible considerations relevant at the time of the woman's return to screening in 2010 was then presented, and again respondents asked to select all that applied. Questionnaires for controls included all the applicable questions from the PNA questionnaire. All questionnaires gathered demographic information including age, level of education, area of residence, membership of private health insurance and eligibility for means tested general medical services (GMS). ${ }^{20}$ Questionnaires were first piloted to five women in each of the four cohorts to assess potential difficulties in comprehension or completion. The questionnaire was then sent to 2500 women, 625 in each cohort. A final response rate of $75 \%$ was estimated, based on a previous BreastCheck survey of attenders for male radiographer study, ${ }^{21}$ where response rate exceeded $85 \%$.

\section{Ethics}

Ethical approval for the study was granted by the Research Ethics Committee from the Faculty of Public Health Medicine and Faculty of Occupational Medicine in the Royal College of Physicians of Ireland.

\section{Statistical analysis}

The chi square test was used for comparison of proportions. Logistic regression was used to adjust for socio-demographic factors. Welch's tTest was used to compare mean travel times. SAS was used for analysis (version 9.1, SAS, North Carolina, USA).

\section{Power considerations}

The achieved sample size has power of $80 \%$ to detect $9 \%$ difference between PNAs and regular attenders and between First PNAs and Subsequent PNAs.

\section{Socio-demographic variables}

\section{Comparison of First PNAs and First Controls}

As the national rollout of BreastCheck began in 2007 First PNAs and First Controls arise from prevalent screening of women across the full age range of 50-64. A greater proportion of First controls than First PNAs had a family history of cancer, a family history of breast cancer and private health insurance. Significantly more First PNAs had third level education (university level or equivalent) and resided in a rural area, compared to First Controls (Table 1).

\section{Comparison of Subsequent PNAs and Subsequent Controls}

Subsequent PNAs and Subsequent Controls were very similar in regard to socio-demographic variables with the exception of area of residence, where a significantly greater proportion of Subsequent PNAs lived in a rural location when compared to Subsequent Controls (Table 1).

\section{Results}

The overall sample size achieved was 1797 (72\%). The response rate was higher for the control groups (86\% for the Subsequent Controls and $81 \%$ for the First Controls) than for the PNA groups (62\% for the Subsequent PNAs and 58\% for the First PNAs). First PNAs and First Controls were similar in terms of age profile and medical card status (Table 1).

Table 2 compares opinions towards breast cancer screening following the responders' most recent BreastCheck mammogram in 2010. For some this would have been their first mammogram; for others they may have based their opinion on cumulative experiences.

\section{Comparison of First PNAs and First Controls}

Similar proportions of First PNAs and First Controls (45.1\% vs 40.3\%; $\mathrm{P}=0.17$ ) spoke to their own GP about breast cancer sometimes/a lot. Good or Excellent levels of health status was reported in both First PNAs and First Controls (82.9\% vs 83.2\%: $\mathrm{P}=0.90$ ). Significantly more First PNA women who described their health status as Fair or Poor were likely to agree or strongly agree with the statement $I$ would rather 
not know if I had breast cancer than those who consider their health as Excellent or Good (16.7\% vs $9.3 \%, \mathrm{P}=0.09)$. There was a significant difference between First PNAs and First Controls in their attitude to the ability of mammography to find small impalpable lumps. Significantly fewer First PNAs agreed with the statement $A$ mammogram could find a small breast lump even if I cannot feel it. All differences in proportions remained significant after adjustment for socio-demographic factors and family history of cancer (Table 2).

\section{Comparison of Subsequent PNAs and Subsequent Controls}

Similar proportions of Subsequent PNAs and Subsequent Controls (40\% vs 42.7\%; $\mathrm{P}=0.41$ ) spoke to their own GP about breast cancer sometimes/a lot; however a significantly lower proportion of Subsequent PNAs reported health status as excellent or good compared to Subsequent Controls $(72.7 \%$ vs $84.9 \%$; $\mathrm{P}<0.001)$. Significantly more Subsequent PNA women who described their health status as Fair or Poor were likely to agree or strongly agree with the statement $I$ would rather not know if I had breast cancer than those who considered their health as Excellent or Good (23.7\% vs 10.5\%, $\mathrm{P}=0.0015)$.

There was a significant difference between Subsequent PNAs and Subsequent Controls in their attitude to the ability of mammography to find small impalpable lumps. Significantly fewer Subsequent PNAs agreed with the statement $A$ mammogram could find a small breast lump even if I cannot feel it. Additionally significantly more Subsequent PNAs than Subsequent Controls agreed that they would rather not know if they had breast cancer. Significantly more Subsequent Controls

Table 1. Socio-demographic variables; comparisons of First PNAs and Subsequent PNAs with respective controls.

\begin{tabular}{|c|c|c|c|c|c|c|c|c|c|c|}
\hline & & & & & $\mathbf{P}$ & Subs & PNA & Subs & ntrol & $P$ \\
\hline & $\mathbf{N}$ & $\%$ & $\mathbf{N}$ & $\%$ & & $\mathbf{N}$ & $\%$ & $\mathbf{N}$ & $\%$ & \\
\hline Age group & & & & & & & & & & \\
\hline $50-54$ & 176 & 49.4 & 251 & 50.4 & 0.466 & 16 & 4.2 & 26 & 4.8 & 0.885 \\
\hline $55-59$ & 106 & 29.8 & 131 & 26.3 & & 194 & 51.2 & 277 & 51.6 & \\
\hline $60+$ & 74 & 20.8 & 116 & 23.3 & & 169 & 44.6 & 234 & 43.6 & \\
\hline GMS card & 122 & 34.1 & 146 & 29.5 & 0.155 & 124 & 32.7 & 154 & 28.6 & 0.184 \\
\hline Private insurance & 202 & 57.7 & 319 & 64.8 & $0.036^{*}$ & 219 & 59.7 & 344 & 65.0 & 0.103 \\
\hline Third level education & 118 & 33.2 & 118 & 23.6 & $0.002 * *$ & 105 & 28.0 & 147 & 27.4 & 0.835 \\
\hline Area of residence & & & & & & & & & & \\
\hline Rural & 131 & 37.3 & 255 & 51.4 & $<0.001^{* *}$ & 146 & 38.9 & 196 & 36.4 & $0.009 * *$ \\
\hline Town & 111 & 31.6 & 142 & 28.6 & & 137 & 36.5 & 161 & 29.9 & \\
\hline City & 109 & 31.1 & 99 & 20.0 & & 92 & 24.5 & 181 & 33.6 & \\
\hline $\begin{array}{l}\text { Family history } \\
\text { of breast cancer }\end{array}$ & 88 & 24.8 & 154 & 31.3 & $0.038^{*}$ & 100 & 26.5 & 162 & 30.5 & 0.192 \\
\hline $\begin{array}{l}\text { Family history } \\
\text { of cancer }\end{array}$ & 220 & 63.2 & 360 & 72.7 & $0.003^{* *}$ & 267 & 70.8 & 378 & 70.9 & 0.975 \\
\hline
\end{tabular}

First PNA: failed to attend BreastCheck appointment in 2007/08; attended in 2010; First Control: attended first invited appointment with BreastCheck in 2010; Subsequent PNA: attended BreastCheck appointment in 2006 or earlier, failed to attend in 2007/08; attended in 2010; Subsequent Control: attended all BreastCheck appointments from 2000-2010. ${ }^{*} \mathrm{P}<0.05 ;{ }^{* *} \mathrm{P}<0.01$.

Table 2. Agreement with statements regarding breast cancer screening, following most recent mammogram in 2010

\begin{tabular}{|c|c|c|c|c|c|c|c|c|}
\hline \multirow[t]{2}{*}{ Statement } & \multicolumn{8}{|c|}{ Percentage agreeing/strongly agreeing with statement } \\
\hline & $\begin{array}{l}\text { First } \\
\text { PNA }\end{array}$ & $\begin{array}{c}\text { First } \\
\text { Control }\end{array}$ & $\begin{array}{l}\text { Unadjusted } \\
\text { OR ( } 95 \% \mathrm{CI})\end{array}$ & $\begin{array}{l}\text { Adjusted OR } \pm \\
(95 \% \mathrm{CI})\end{array}$ & $\begin{array}{l}\text { Subsequent } \\
\text { PNA }\end{array}$ & $\begin{array}{l}\text { Subsequent } \\
\text { Control }\end{array}$ & $\begin{array}{l}\text { Unadjusted } \\
\text { OR (95\% CI) }\end{array}$ & $\begin{array}{l}\text { Adjusted OR } \\
\pm(95 \% \mathrm{CI})\end{array}$ \\
\hline $\begin{array}{l}\text { A mammogram could } \\
\text { find a small breast lump } \\
\text { even if I cannot feel it }\end{array}$ & $90.7 \%$ & $94.6 \%$ & $\begin{array}{c}0.56^{*} \\
(0.33-0.95)\end{array}$ & $\begin{array}{c}0.58 * \\
(0.33-1.00)\end{array}$ & $88.2 \%$ & $94.5 \%$ & $\begin{array}{c}0.43^{* *} \\
(0.27-0.70)\end{array}$ & $\begin{array}{c}0.42 * * \\
(0.26-0.69)\end{array}$ \\
\hline $\begin{array}{l}\text { Having treatment is better } \\
\text { than having the disease }\end{array}$ & $94.4 \%$ & $95.0 \%$ & $\begin{array}{c}0.89 \\
(0.49-1.65)\end{array}$ & $\begin{array}{c}0.92 \\
(0.49-1.73)\end{array}$ & $96.8 \%$ & $97.8 \%$ & $\begin{array}{c}0.70 \\
(0.31-1.57)\end{array}$ & $\begin{array}{c}0.72 \\
(0.31-1.65)\end{array}$ \\
\hline $\begin{array}{l}\text { I would rather not know if } \\
\text { I had breast cancer }\end{array}$ & $10.6 \%$ & $11.7 \%$ & $\begin{array}{c}0.89 \\
(0.58-1.39)\end{array}$ & $\begin{array}{c}0.84 \\
(0.53-1.33)\end{array}$ & $14.4 \%$ & $7.7 \%$ & $\begin{array}{c}2.03^{* *} \\
(1.31-3.14)\end{array}$ & $\begin{array}{c}1.94 * * \\
(1.24-3.05)\end{array}$ \\
\hline $\begin{array}{l}\text { Breast cancer can be } \\
\text { cured if found early }\end{array}$ & $92.0 \%$ & $92.7 \%$ & $\begin{array}{c}0.90 \\
(0.54-1.50)\end{array}$ & $\begin{array}{c}0.94 \\
(0.55-1.60)\end{array}$ & $90.9 \%$ & $93.5 \%$ & $\begin{array}{c}0.69 \\
(0.42-1.14)\end{array}$ & $\begin{array}{c}0.68 \\
(0.41-1.13)\end{array}$ \\
\hline $\begin{array}{l}\text { Having a mammogram } \\
\text { is painful }\end{array}$ & $31.8 \%$ & $31.7 \%$ & $\begin{array}{c}1.01 \\
(0.75-1.35)\end{array}$ & $\begin{array}{c}1.04 \\
(0.77-1.41)\end{array}$ & $34.2 \%$ & $33.1 \%$ & $\begin{array}{c}1.05 \\
(0.80-1.40)\end{array}$ & $\begin{array}{c}1.02 \\
(0.77-1.36)\end{array}$ \\
\hline $\begin{array}{l}\text { Having a mammogram } \\
\text { is embarrassing }\end{array}$ & $15.1 \%$ & $15.3 \%$ & $\begin{array}{c}0.98 \\
(0.67-1.44)\end{array}$ & $\begin{array}{c}0.99 \\
(0.66-1.46)\end{array}$ & $16.9 \%$ & $12.8 \%$ & $\begin{array}{c}1.39 \\
(0.96-2.03)\end{array}$ & $\begin{array}{c}1.34 \\
(0.91-1.99)\end{array}$ \\
\hline $\begin{array}{l}\text { Having a mammogram } \\
\text { is quick }\end{array}$ & $91.6 \%$ & $91.7 \%$ & $\begin{array}{c}0.99 \\
(0.60-1.63)\end{array}$ & $\begin{array}{c}1.09 \\
(0.64-1.83)\end{array}$ & $92.4 \%$ & $94.8 \%$ & $\begin{array}{c}0.67 \\
(0.39-1.15)\end{array}$ & $\begin{array}{c}0.62 \\
(0.36-1.09)\end{array}$ \\
\hline $\begin{array}{l}\text { My family/friends have positive } \\
\text { experiences of breast screening }\end{array}$ & $73.7 \%$ & $76.4 \%$ & $\begin{array}{c}0.86 \\
(0.62-1.19)\end{array}$ & $\begin{array}{c}0.92 \\
(0.66-1.29)\end{array}$ & $72.7 \%$ & $80.8 \%$ & $\begin{array}{c}0.63^{* *} \\
(0.46-0.87)\end{array}$ & $\begin{array}{c}0.61^{* *} \\
(0.44-0.85)\end{array}$ \\
\hline
\end{tabular}

Adjusted for age, urban/rural residence, GMS eligibility, private medical insurance status, education level, family history of cancer and family history of breast cancer. ${ }^{*} \mathrm{P}<0.05{ }^{*} \mathrm{P}<0.01$. 
agreed that their family or friends have had positive experiences of breast screening. All differences in proportions again remained significant after adjustment for socio-demographic factors and family history of cancer (Table 2).

The interrelationships between responses to the first four statements in table two regarding attitudes to breast cancer and beliefs about screening were explored. Agreement with the statement I would rather not know I had breast cancer was not significantly associated with agreement with the other three.

\section{Comparison of First PNAs and First Controls}

Among the considerations at the time of first invite (2007/08 for First PNAs and 2010 for First Controls) the following issues were reported significantly more by First Controls compared to First PNAs: feeling shy; thought mammogram would be/was unpleasant; thought the mammogram would be/was painful; found the invitation reassuring; fear of operation; GP examines breast; GP will refer if needed and had no symp- toms. Additionally, significantly more First Controls than First PNAs had concerns that breasts were too large or too small and had never heard of BreastCheck before I got invitation (Table 3). Following exclusion of women from the analysis who had received a mammogram previously (outside of the national programme), concerns about breasts being too large or too small were no longer significantly different $(\mathrm{P}=0.114)$, whereas the proportions confirming I thoughtearlier mammogram would be/was painful remained significantly greater among First Controls than First PNAs (18.7\% vs $15.3 \%, \mathrm{P}<0.001)$.

The only consideration at the time of first invite (2007/08 for First PNAs and 2010 for First Controls) which was reported significantly more by First PNAs compared to First Controls was could not reschedule appointment. While a small number of controls stated they could not reschedule appointment for some reason, they still attended the scheduled appointment.

Some questions were only relevant to PNAs to probe the reasons that they did not attend their previous appointment. The following reasons

Table 3. Considerations at time of missed appointment (PNAs)/attended appointment (Controls).

\begin{tabular}{|c|c|c|c|c|c|c|c|c|c|c|}
\hline $\begin{array}{l}\text { Time of first invitation } \\
\text { Time of missed appointment }\end{array}$ & \multicolumn{2}{|c|}{$\begin{array}{l}(2007 / 08) \\
(2007 / 08) \\
\text { First PNA }\end{array}$} & \multicolumn{2}{|c|}{$\begin{array}{l}(2010) \\
- \\
\text { First Control }\end{array}$} & $\mathbf{P}$ & \multicolumn{2}{|c|}{$\begin{array}{c}\text { (2006 or earlier) } \\
(2007 / 08) \\
\text { Subsequent PNA }\end{array}$} & \multicolumn{2}{|c|}{$\begin{array}{l}\text { (2008 or earlier) } \\
- \\
\text { Subsequent Control } \\
\text { N }\end{array}$} & $P$ \\
\hline Felt shy & 16 & $(4.4)$ & 65 & $(12.9)$ & $<0.001^{* *}$ & 3 & $(0.8)$ & 43 & $(8.0)$ & $<0.001^{* *}$ \\
\hline Not comfortable asking for time off work & 12 & $(3.3)$ & 20 & $(4.0)$ & 0.604 & 12 & $(3.1)$ & 27 & $(5.0)$ & 0.151 \\
\hline No screening at weekends/evenings & 13 & $(3.6)$ & 27 & $(5.4)$ & 0.216 & 10 & $(2.6)$ & 28 & $(5.2)$ & $0.047^{*}$ \\
\hline Loss of wages & 5 & $(1.4)$ & 9 & $(1.8)$ & 0.634 & 6 & $(1.5)$ & 13 & $(2.4)$ & 0.358 \\
\hline Could not reschedule appointment & 21 & $(5.8)$ & 5 & $(1.0)$ & $<0.001^{* *}$ & 32 & $(8.2)$ & 2 & $(0.4)$ & $<0.001^{* *}$ \\
\hline Trip too difficult & 24 & $(6.6)$ & 37 & $(7.3)$ & 0.671 & 25 & $(6.4)$ & 15 & $(2.8)$ & $0.007^{* *}$ \\
\hline Disliked attending mobile & 7 & $(1.9)$ & 16 & $(3.2)$ & 0.257 & 11 & $(2.8)$ & 25 & $(4.6)$ & 0.160 \\
\hline Breasts too large or too small & 5 & $(1.4)$ & 19 & $(3.8)$ & $0.034^{*}$ & 7 & $(1.5)$ & 30 & $(5.6)$ & $0.004^{* *}$ \\
\hline I thought/Earlier mammogram would be/was unpleasant & 34 & $(9.3)$ & 137 & $(27.2)$ & $<0.001^{* *}$ & 32 & $(8.2)$ & 51 & $(9.4)$ & 0.521 \\
\hline I thought/Earlier mammogram would be/was painful & 17 & $(4.7)$ & 94 & (18.7) & $<0.001^{* *}$ & 28 & $(7.2)$ & 76 & $(14.1)$ & $0.001^{* *}$ \\
\hline I thought/Earlier mammogram would be/was too long & 11 & $(3.0)$ & 17 & $(3.4)$ & 0.773 & 0 & $(0.0)$ & 4 & $(0.7)$ & 0.089 \\
\hline Too busy & 42 & (11.5) & 66 & $(13.1)$ & 0.493 & 55 & $(14.1)$ & 89 & $(16.5)$ & 0.330 \\
\hline Invitation reassuring & 14 & $(3.8)$ & 373 & $(74.0)$ & $<0.001^{* *}$ & 18 & $(4.6)$ & 396 & $(73.3)$ & $<0.001^{* *}$ \\
\hline Invitation unclear & 3 & $(0.8)$ & 2 & $(0.4)$ & 0.412 & 0 & $(0.0)$ & 2 & $(0.4)$ & 0.230 \\
\hline Invitation frightening & 28 & $(7.7)$ & 39 & $(7.7)$ & 0.980 & 9 & $(2.3)$ & 32 & $(5.91)$ & $0.008^{* *}$ \\
\hline Concern re radiation & 12 & $(3.3)$ & 27 & $(5.4)$ & 0.148 & 12 & $(3.1)$ & 34 & $(6.3)$ & $0.026^{*}$ \\
\hline Fear of operation & 25 & $(6.9)$ & 77 & $(15.3)$ & $<0.001^{* *}$ & 4 & $(1.0)$ & 68 & (12.6) & $<0.001^{* *}$ \\
\hline GP examines breasts & 21 & $(5.8)$ & 83 & $(16.5)$ & $<0.001^{* *}$ & 14 & $(3.6)$ & 38 & $(7.0)$ & $0.025^{*}$ \\
\hline GP will refer if needed & 8 & $(2.2)$ & 30 & $(6.0)$ & $0.008^{* *}$ & 5 & $(1.3)$ & 12 & $(2.2)$ & 0.293 \\
\hline No symptoms & 18 & $(4.9)$ & 193 & (38.3) & $<0.001^{* *}$ & 24 & $(6.2)$ & 141 & $(26.1)$ & $<0.001^{* *}$ \\
\hline Never heard of BreastCheck before I got the invitation & 12 & $(3.3)$ & 32 & $(6.4)$ & $0.043^{*}$ & - & - & - & - & $\mathrm{N} / \mathrm{A}$ \\
\hline \multicolumn{11}{|l|}{ Options for PNAs only (not relevant to controls) } \\
\hline Already had mammogram elsewhere & 120 & $(33.3)$ & - & - & N/A & 55 & $(14.1)$ & - & - & N/A \\
\hline Screening does not work & 1 & $(0.3)$ & - & - & N/A & 1 & $(0.3)$ & - & - & $\mathrm{N} / \mathrm{A}$ \\
\hline Not interested & 3 & $(0.8)$ & - & - & N/A & 0 & $(0.0)$ & - & - & $\mathrm{N} / \mathrm{A}$ \\
\hline Did not receive invite & 42 & $(11.5)$ & - & - & N/A & 19 & $(4.9)$ & - & - & $\mathrm{N} / \mathrm{A}$ \\
\hline On holiday & 16 & $(4.4)$ & - & - & N/A & 45 & $(11.6)$ & - & - & $\mathrm{N} / \mathrm{A}$ \\
\hline Ill/hospitalised & 12 & $(3.3)$ & - & - & N/A & 42 & $(10.8)$ & - & - & $\mathrm{N} / \mathrm{A}$ \\
\hline Postponed to next round & 61 & $(16.8)$ & - & - & N/A & 73 & $(18.8)$ & - & - & $\mathrm{N} / \mathrm{A}$ \\
\hline Forgot appointment & 45 & $(12.4)$ & - & - & N/A & 72 & $(18.5)$ & - & - & $\mathrm{N} / \mathrm{A}$ \\
\hline Already having treatment for cancer & 8 & $(2.2)$ & - & - & N/A & 8 & $(2.1)$ & - & - & N/A \\
\hline
\end{tabular}

$* \mathrm{P}<0.05 * * \mathrm{P}<0.01$ 
were given by First PNAs: already had a mammogram elsewhere; did not receive invite; on holiday; illhospitalised; postponed to next round; forgot appointment; already having treatment for cancer; not interested; screening does not work (Table 3 ).

\section{Comparison of Subsequent PNAs and Subsequent Controls}

Subsequent PNAs were also asked to consider possible reasons for their missed appointment in 2007/08. Subsequent Controls were asked to highlight issues which they considered before or during their attended appointments. Among the considerations which were reported significantly more by Subsequent Controls compared to Subsequent PNAs were feeling shy; screening was not available at weekends or evenings; breasts were too large or too small; thought the mammogram would be/was painful; found the invitation reassuring; the invitation was frightening; fear of operation; concerns about radiation; GP examines breasts and had no symptoms.

The only two considerations which were reported significantly more by Subsequent PNAs compared to Subsequent Controls were; could not reschedule appointment and trip too difficult. Again while a small number of controls stated they could not reschedule appointment for some reason, they still attended the scheduled appointment (Table 3).

Some questions were only relevant to Subsequent PNAs to probe the reasons that they did not attend their previous appointment and the following reasons were given: already had a mammogram elsewhere; did not receive invite; on holiday; illhospitalised; postponed to next round; forgot appointment; already having treatment for cancer and screening does not work (Table 3 ).

Table 4 outlines considerations pertinent to PNA women at the time of re-invitation to screening in 2010 . Among the more frequent were; $I$ am older; I made sure to remember the appointment this time; Breast cancer is now of particular concern to me; All illness is now of more concern to me; I was able to reschedule to a suitable time. First PNAs were significantly more likely to consider the following items than Subsequent PNAs: My GP advised me to attend; My family or friends advised me to attend; I heard good things about BreastCheck; I had heard more about BreastCheck; The invitation seemed more clear this time (Table 4).

Upon examination of mean travel times to the screening unit we found that there were very small but statistically significant differences between First PNAs compared to First Controls (27.8 minutes vs 24.5 minutes; $\mathrm{P}=0.016$ ). When examining reasons for First PNAs attending their 2010 screening appointment; 11.8\% of First PNAs cited Trip to screening centre easier because different location, as one of the reasons for attending, while 5.5\% of First PNAs agreed that the Trip to screening centre (was) easier because better transport available now (Table 4).

There were similar very small but statistically significant differences between Subsequent PNAs compared to Subsequent Controls also (27.6 minutes vs 24.7 minutes; $\mathrm{P}=0.043$ ). For Subsequent PNAs attending their 2010 screening appointment; 10\% cited Trip to screening centre easier because different location, as one of the reasons for attending, while 7.5\% of Subsequent PNAs agreed that the Trip to screening centre (was) easier because better transport available now (Table 4).

\section{Discussion}

\section{Methodological limitations}

Maintenance of breast screening uptake is a serious challenge. The large sample size and the response rate of $72 \%$ add weight to our findings and is comparable to other published postal surveys. ${ }^{22}$ A limitation is the poorer response rate in PNAs overall (60\%) and particularly First PNAs (58\%). While the variation between sub-groups does not impact on the validity or reliability of the statistical analysis, it does highlight the correlation between non-participation in the programme and willingness to complete the questionnaire. 489 (27\%) respondents provid-

Table 4. Considerations at time of return to screening in 2010.

\begin{tabular}{|c|c|c|c|c|c|}
\hline & \multicolumn{2}{|c|}{ First PNAs } & \multicolumn{2}{|c|}{ Subsequent PNAs } & \multirow[t]{2}{*}{$\mathbf{P}$} \\
\hline & $\mathbf{N}$ & $\%$ & $\mathbf{N}$ & $\%$ & \\
\hline I am older & 129 & 35.4 & 115 & 29.6 & 0.085 \\
\hline I made sure I remembered the appointment this time & 86 & 23.6 & 113 & 29 & 0.092 \\
\hline I rang up and was able to reschedule appointment to suitable time & 64 & 17.6 & 80 & 20.6 & 0.298 \\
\hline All illnesses now of more concern to me & 60 & 16.5 & 74 & 19 & 0.363 \\
\hline Breast cancer in particular is now of more concern to me & 82 & 22.5 & 73 & 18.8 & 0.202 \\
\hline My family or friends advised me to attend & 81 & 22.3 & 59 & 15.2 & $0.013^{*}$ \\
\hline My GP advised me to attend & 46 & 12.6 & 18 & 4.6 & $<0.001^{* *}$ \\
\hline I had heard more about BreastCheck & 56 & 15.4 & 16 & 4.1 & $<0.001^{* *}$ \\
\hline I had heard good things about BreastCheck & 105 & 28.8 & 53 & 13.6 & $<0.001^{* *}$ \\
\hline Serious personal illness or hospitalised in past two years & 14 & 3.8 & 20 & 5.1 & 0.392 \\
\hline A friend or family member got cancer in past two years & 51 & 14.0 & 49 & 12.6 & 0.568 \\
\hline I had heard of celebrities developing breast cancer & 19 & 5.2 & 17 & 4.4 & 0.585 \\
\hline Trip to screening centre easier because different location & 43 & 11.8 & 39 & 10 & 0.431 \\
\hline Trip to screening centre easier because better transport available now & 20 & 5.5 & 29 & 7.5 & 0.276 \\
\hline I was less busy at work/home & 35 & 9.6 & 34 & 8.7 & 0.677 \\
\hline Invitation seemed more reassuring this time & 19 & 5.2 & 18 & 4.6 & 0.707 \\
\hline Invitation seemed more clear this time & 21 & 5.8 & 10 & 2.6 & $0.027^{*}$ \\
\hline I had symptoms & 11 & 3.0 & 13 & 3.3 & 0.803 \\
\hline
\end{tabular}

First PNAs: failed to attend BreastCheck appointment in 2007/08; attended in 2010; Subsequent PNAs: attended BreastCheck appointment in 2006 or earlier, failed to attend in 2007/08; attended in 2010. *P<0.05 ${ }^{* *} \mathrm{P}<0.01$. 
ed their contacts details for a potential follow up study, and of these, two women had sent the questionnaire back twice. The duplicate questionnaires were excluded from the dataset. Women who were recalled for further tests after having a mammogram were excluded from the sample; therefore any reasons for non-attendance resulting from being recalled for assessment were not examined. Questionnaires were based on internationally published work in the area of non-attendance. Due to the explorative nature of the study, there was scope given for women to add additional comments. It is acknowledged that asking women to recall why they did not attend their appointment two years prior to their 2010 screening may raise some reliability concerns of answers provided due to the length of time since missed appointment; also a woman's current view of breast screening may cognitively bias her reflection of previous decision making.

While there is much written about non-attenders we were unable to find any other study that has addressed specifically why intermittent attenders return to breast screening. These women differ from persistent non-attenders as they have returned to screening. In common with other studies, ${ }^{9,23,24}$ controls (women who attend mammographic screening) were more likely to have a family history of cancer or breast cancer than intermittent attenders. Subsequent PNAs who attended once and then skipped one or several screening rounds before returning in 2010 were significantly less likely than the controls to report their health status as good or excellent. This finding corresponds with the main considerations given for returning in 2010 i.e. all illness is now of more concern to me, breast cancer is now of particular concern to me. These findings support a US study which found that breast cancer worry may motivate screening behaviour rather than deter it. ${ }^{25} \mathrm{~A}$ 2004 critical review of twenty two studies regarding how fear, anxiety and worry influence cancer screening behaviour found no conclusive evidence of whether these emotions act as a barrier or facilitator of screening. ${ }^{26}$ Compared to PNAs, women who have attended all invited appointments were significantly more likely to be concerned about shyness, size of breasts, pain of mammogram and fear of operation at time of first invite; however such fears did not deter women from attending. First Controls were additionally concerned about unpleasantness of mammogram, while Subsequent Controls had concerns about radiation and found the invitation frightening. These findings may highlight unexpected concerns women only become aware of after attending screening, although these concerns do not seem to create a barrier. These findings lend support to research suggesting the need for more transparency in the information provided to women and its contribution to informed decision making. ${ }^{27-29}$ However a substantial proportion of the population must participate for screening programme to operate successfully. Recent research offers conflicting evidence on the impact that the provision of comprehensive information on the risks of screening has on uptake. A study in Switzerland has shown that informing potential participants about the risks of cancer screening may reduce participation regardless of beneficial information provided, ${ }^{30}$ while a randomised controlled trial of a colorectal cancer screening programme in Germany showed that the provision of evidence based risk information increased informed choices and improved knowledge, with no adverse affects on uptake of screening. ${ }^{31}$ An outcome of this study highlights that Subsequent Controls, having experience of the programme and who by default are more informed of the process and any potentially negative aspects, are not deterred from attending subsequent rounds.

A recent UK study has found that cancer screening uptake is generally lower in the urban setting than in rural areas, ${ }^{10}$ however rural residency was proportionally higher among PNAs in this study compared to respective controls, similar to the findings in other comparative studies in the US and Canada. ${ }^{11,12}$ Residing in a rural area was a deterrent to attendance within this cohort even though mobile units are located at sites all over the country; First PNAs cited the trip would be too difficult as a reason for non-attendance and this was reiterated by Subsequent PNAs as a reason for non attendance, after attending a first time. There were very small but significant differences in mean length of time taken to travel to the screening unit, longer for PNAs compared to controls in both first and subsequent women. A study in Northern Ireland examining access found that while more non-attenders did not have access to private transport, few (4\%) expressed a preference for more accessible clinics. ${ }^{13}$ This UK study along with a Canadian study, ${ }^{11}$ finding lower rural uptake of screening, conclude that the deterrent is more likely the attitude of rural residents towards breast screening rather than access. On the other hand, both First PNAs and Subsequent PNAs in this study cited Trip to screening centre easier because different location and Trip to screening centre easier because better transport available now as reasons for attendance in 2010.

A study of 10,228 people across nine European countries found that the vast majority of citizens systematically overestimate the benefits of mammography screening. ${ }^{32}$ Similar findings were reported in Switzerland, US and UK. ${ }^{22,33}$ An Australian study examining the effects of knowledge and beliefs on uptake of mammography found that women who believed mammograms at best were only somewhat effective, were unsure or did not think that mammograms save lives were significantly more likely to have never had a mammogram. ${ }^{34}$ In this study we found that significantly fewer First PNAs and Subsequent PNAs compared to their respective controls believe that a mammogram could find a small impalpable lump, suggesting a lack of trust in the effectiveness of mammography among PNAs. Significantly more Subsequent PNAs than Subsequent Controls reported that they would rather not know if they had breast cancer suggesting some denial or fatalism in this group. A US study examining the influence of fatalism on cancer screening participation found that women with a fatalistic attitude also had a family history of breast cancer, believed that not much could be done to prevent breast cancer, believed that breast cancer could not be cured if found early and believed that treatment could be worse than the disease. ${ }^{17}$ Our study also examined similar beliefs but we found that there were no significant correlations with PNA women who would rather not know if they have breast cancer; however these women were significantly more likely to consider their health status as poor or fair.

Family and friends appear to have a strong positive influence on Subsequent Controls commitment to re-attendance. In addition First PNAs were significantly more likely than Subsequent PNAs to have returned to screening because their family and friends advised them to attend. In a study of 300 attenders and 300 non-attenders in Northern Ireland, both groups obtained information more often from friends and relatives than from official sources. ${ }^{35}$ These findings reinforce the importance of word of mouth as a means of screening promotion, supporting initiatives such as the New England Tell a friend programme, ${ }^{36}$ and similar schemes in the US. ${ }^{37,38}$ These initiatives have guided various community educational drives carried out by the screening promotion team in BreastCheck. While word of mouth is an important influence, such initiatives aim to ensure that information passed through word of mouth is based on factual information, rather than emotional and personal reasons. Consedine et al. identified four studies where women claimed to be more likely to get a mammogram if their physician recommended it, ${ }^{26}$ which supports the findings in this study where both First PNAs and Subsequent PNAs listed My GP advised me to attend as a reason for returning to screening; however GPs were significantly more influential for First PNAs than Subsequent PNAs. 


\section{Conclusions}

There is little previously published regarding factors influencing such intermittent attendance at breast screening. Intermittent attenders do not fit typical socio-demographic patterns of non-attenders at screening; persistence in recommendation by GP and word of mouth are importance influences on women's return to screening, as are logistical considerations. Fear, anxiety and worry seem to act as a facilitator of screening rather than an inhibitor.

Correspondence: Padraic Fleming, Programme Evaluation Unit, National Cancer Screening Service, King’s Inn House, 200 Parnell Street, Dublin, Ireland.

Tel. +353.1865 .300 - Fax: +353.018 .659 .333 .

E-mail: peu@cancerscreening.ie

Key words: non-attender, population screening, breast cancer, uptake.

Contributions: PFl, conception and design, data collection, data analysis and interpretation, article drafting, revision and final approval; SON, conception and design, statistical data analysis, interpretation of data, critical revision,

final approval; TM, conception and design, interpretation of data, critical revision, final approval; MO, conception and design, data analysis, critical revision, final approval; PFi, conception and design, data analysis and interpretation, critical revision, final approval.

Conflict of interests: the authors declare no potential conflict of interests.

Received for publication: 1 May 2013.

Accepted for publication: 17 June 2013.

CCopyright P. Fleming et al., 2013

Licensee PAGEPress, Italy

Journal of Public Health Research 2013; 2:e14

doi:10.4081/jphr.2013.e14

This work is licensed under a Creative Commons Attribution NonCommercial 3.0 License (CC BY-NC 3.0).

\section{References}

1. Tabár L, Vitak B, Chen THH, et al. Swedish two-county trial: impact of mammographic screening on breast cancer mortality during 3 decades. Radiology 2011;260:658-63.

2. Van Schoor G, Moss SM, Otten JDM, et al. Increasingly strong reduction in breast cancer mortality due to screening. Br J Cancer 2011;104:910-4.

3. Kalager M, Zelen M, Langmark F, Adami HO. Effect of screening mammography on breast-cancer mortality in Norway. N Engl J Med 2010;363:1203-10.

4. Perry N, Broeders M, De Wolf C, et al. European Guidelines for quality assurance in breast screening and diagnosis. Fourth Edition. Luxembourg: Office for Official Publications of the European Communities 2006.

5. BreastCheck. Programme Report 2010/11. National Cancer Screening Service, Dublin, 2012.

6. Törnberg S, Kemetli L, Svane G, et al. Pattern of participation in a cohort aged 50-60 at first invitation to the service-screening programme with mammography in Stockholm county, Sweden. Prev Med 2005;41:728-33.

7. Barr JK, Franks AL, Lee NC, et al. Factors associated with continued participation in mammography screening. Prev Med 2001; 33:661-7.

8. Elwood M, McNoe B, Smith T, et al. Once is enough - why some women do not continue to participate in a breast cancer screening programme. N Z Med J 1998;111:180-3.
9. Staniscia T, Manzoli LM, Di Giovanni P, et al. Factors related to the uptake of breast cancer screening (mammography and breast ultrasound): a retrospective survey on a sample of resident women, 50-70 years aged, from Abruzzo region. Ann Ig 2003;15:1063-75.

10. Kinnear H, Rosato M, Mairs A, et al. The low uptake of breast screening in cities is a major public health issue and may be due to organisational factors: a Census-based record linkage study. Breast 2011;20:460-3.

11. McDonald JT, Sherman A. Determinants of mammography use in rural and urban regions of Canada. Can J Rural Med 2010;15:52-60.

12. Doescher MP, Jackson JE. Trends in cervical and breast cancer screening practices among women in rural and urban areas of the United States. J Public Health Manag Pract 2009;15:200-9.

13. Kee F, Telford AM, Donaghy P, O'Doherty A. Attitude or access: reasons for not attending mammography in Northern Ireland. Eur J Cancer Prev 1992;1:311-5.

14. Mooney T, Duignan A, Kiernan D, Fitzpatrick P. Round skipping in breast screening in BreastCheck - effect on key outcome predictors. Paper presented at the Pan-European Network Meeting ECCG-ECN-EUROCOURSE; 2010 May 20-2; Warsaw, Poland.

15. Lopez ED, Khoury AJ, Dailey AB, et al. Screening mammography: a cross-sectional study to compare characteristics of women aged 40 and older from the deep South who are current, overdue, and never screeners. Womens Health Issues 2009;19:434-45.

16. Klassen AC, Washington C. How does social integration influence breast cancer control among urban African-American women? Results from a cross-sectional survey. BMC Womens Health 2008;8:4.

17. Hall AG, Khoury AJ, Lopez ED, et al. Breast cancer fatalism: the role of women's perceptions of the health care system. J Health Care Poor Underserved 2008;19:1321-35.

18. Schueler KM, Chu PW, Smith-Bindman R. Factors associated with mammography utilization: a systematic quantitative review of the literature. J Womens Health 2008;17;1477-98.

19. Esteva M, Ripoll J, Leiva A, et al. Determinants of non attendance to mammography program in a region with high voluntary health insurance coverage. BMC Public Health 2008;8;387.

20. Health Service Executive. What is the roles of PCRS? Available from: http://www.hse.ie/portal/eng/staff/PCRS/About_PCRS/. Accessed on: October 2011.

21. Fitzpatrick $\mathrm{P}$, Winston A, Mooney T. Radiographer gender and breast-screening uptake. Br J Cancer 2008;98:1759-61.

22. Chamot E, Perneger TV. Misconceptions about efficacy of mammography screening:a public health dilemma. J Epidemiol Commun Health 2001;55:799-803.

23. Cohen M. Breast cancer early detection, health beliefs, and cancer worries in women randomly selected with and without a family history of breast cancer. Psychooncology 2006;15:873-83.

24. Antill YC, Reynolds J, Young MA, et al. Screening behaviour in women at increased familial risk for breast cancer. Fam Cancer 2006;5:359-68.

25. Hay JL, McCaul KD, Magnan RE. Does worry about breast cancer predict screening behaviour? A meta-analysis of the prospective evidence. Prev Med 2006;42:401-8.

26. Consedine NS, Magai C, Krivoshekova YS, et al. Fear, anxiety, worry, and breast cancer screening behavior: a critical review. Cancer Epidemiol Biomarkers Prev 2004;13:501-10.

27. Ward J. Population-based mammographic screening: does informed choice require any less than full disclosure to individuals of benefits, harms, limitations and consequences? Aust $\mathrm{N} \mathrm{Z} \mathrm{J}$ Public Health 1999;23:301-4.

28. Gummersbach E, Piccoliori G, Zerbe CO, et al. Are women getting relevant information about mammography screening for an informed consent: a critical appraisal of information brochures 
used for screening invitation in Germany, Italy, Spain and France. Eur J Public Health 2010;20:409-14.

29. Weller DP, Patnick J, McIntoch HM, Dietrich AJ. Uptake in cancer screening programmes. Lancet Oncology 2009;10:693-9.

30. Perneger TV, Cullati S, Schiesari L, Charvet-Bérard A. Impact of information about risks and benefits of cancer screening on intended participation. Eur J Cancer 2010;46:2267-74.

31. Steckelberg A, Hülfenhaus C, Haastert B, Mühlhauser I. Effect of evidence based risk information on informed choice in colorectal cancer screening: randomised controlled trial. BMJ 2011;342:d3193.

32. Gigerenzer G, Mata J, Frank R. Public knowledge of benefits of breast and prostate cancer screening in Europe. J Natl Cancer Inst 2009;101:1216-20.

33. Domenighetti G, D’Avanzo B, Egger M, et al. Women's perception of benefits of mammography screening: population-based survey in four countries. Int J Epidemiol 2003;32:816-21.
34. Achat H, Close G, Taylor R. Who has regular mammograms? Effects of knowledge, beliefs, socioeconomic status, and health-related factors. Prev Med 2005;41;312-20.

35. Kee F, Telford AM, Donaghy P, 0'Doherty A. Enhancing mammography uptake: who do women listen to? Eur J Cancer Prev 1993;2:3742.

36. Passanisi N, Prout M, Holm LJ. The New England division Tell A Friend program implementation evaluation. Cancer Pract 2001;9 Suppl 1:S64-71.

37. Kiger H. Outreach to multiethnic, multicultural, and multilingual women for breast cancer and cervical cancer education and screening: a model using professional and volunteer staffing. Fam Community Health 2003;26:307-18.

38. Bencivenga M, DeRubis S, Leach P, Lotito L, Shoemaker C, Lengerich EJ. Community partnerships, food pantries, and an evidence-based intervention to increase mammography among rural women. J Rural Health. 2008;24:91-5. 